Atos de Pesquisa em Educação - ISSN 1809-0354

Blumenau, v.14, n.2, supl.1, p.815-840, out./nov. 2019

DOI: http://dx.doi.org/10.7867/1809-0354.2019v14n2s1p815-840

\title{
EVASÃO NOS CURSOS DE FORMAÇÃO DE PROFESSORES: O CASO DE UM CURSO DE LICENCIATURA EM QUÍMICA
}

\section{EVASIÓN EN LOS CURSOS DE FORMACIÓN DE PROFESORES: EL CASO DE UN CURSO DE LICENCIATURA EN QUÍMICA}

\section{EVASION IN TEACHER TRAINING COURSES: THE CASE OF A COURSE OF GRADUATION IN CHEMISTRY}

DEIMLING, Natalia Neves Macedo natanema@gmail.com Universidade Tecnológica Federal do Paraná ORCID: http://orcid.org/0000-0001-8394-3132

SILVA, Daniele Cristina da danicris2006@hotmail.com Universidade Tecnológica Federal do Paraná ORCID: https://orcid.org/0000-0001-5624-9321

\begin{abstract}
RESUMO Com o objetivo de analisar e discutir os possíveis fatores desencadeadores da evasão acadêmica nos cursos de licenciatura foi analisado o caso de um curso de Licenciatura em Química de uma Universidade Federal brasileira entre os anos de 2016 e 2017. Para a análise dessa problemática, o estudo contou com as visões e percepções dos próprios estudantes que desistiram do curso. Um questionário foi enviado a 214 estudantes que, entre o primeiro semestre de 2011 e o primeiro semestre de 2016 , evadiram-se do curso. Ao todo, foram obtidas 59 participações. A partir da análise dos dados, podemos observar que vários fatores têm desencadeado a evasão dos alunos no curso em questão, dentre eles a ausência de condições que garantam não apenas o seu acesso como também a sua permanência no curso de licenciatura e na futura profissão.
\end{abstract}

Palavras-chave: Evasão. Formação de professores. Licenciatura em Química.

RESUMEN Con el objetivo de analizar y discutir los posibles factores desencadenantes de la evasión académica en los cursos de licenciatura, se analizó el caso de un curso de Licenciatura en Química de una Universidad Federal brasileña entre los años 2016 y 2017. Para el análisis de esta problemática, el estudio contó con las visiones y percepciones de los propios estudiantes que desistieron del curso. Un cuestionario fue enviado a 214 estudiantes que entre el primer semestre de 2011 y el primer semestre de 2016 desistieron del curso. En total se obtuvieron 59 participaciones. A partir del análisis de los datos, podemos observar que varios factores han desencadenado la evasión académica en el curso en cuestión, entre ellos la ausencia de condiciones que garanticen no sólo su acceso, sino también su permanencia en el curso de licenciatura y en la futura profesión.

Palabras clave: La evasión. Formación de profesores. Licenciatura en Química.

ABSTRACT With the objective of analyzing and discussing the possible factors of academic avoidance in undergraduate courses, the case of a degree in Chemistry of a Brazilian Federal University between the years 2016 and 2017 was analyzed. The 
study counted on the visions and perceptions of the students themselves who gave up the course. A questionnaire was sent to 214 students who dropped out of the course between the first half of 2011 and the first half of 2016. In total 59 participations were obtained. From the analysis of the data, we can observe that several factors have triggered the academic evasion in the course in question, among of them the absence of conditions that guarantee not only its access, but also its permanence in the undergraduate course and in the future profession.

Keywords: Evasion. Teacher training. Chemistry graduation.

\section{INTRODUÇÃO}

A evasão acadêmica tem sido um fenômeno complexo comum às Instituições Universitárias, tornando-se objeto de estudo e análise em diferentes países (RODRIGUES et al., 2015). Trata-se de uma preocupação recorrente em qualquer instituição, uma vez que o abandono do curso pode gerar prejuízos financeiros, sociais e acadêmicos. Para o estudante, a evasão também traz prejuízos, uma vez que os recursos financeiros por ele investidos ao iniciar um curso de formação superior e o tempo dedicado para o curso escolhido - e não concluído - poderiam ter sido alocados em atividades que lhe trariam algum retorno mais imediato. Além disso, há também a questão que envolve a frustração pessoal e profissional desse estudante por não ter conseguido concluir o curso (CUNHA; NASCIMENTO; DURSO, 2014; SILVA FILHO et al., 2007). Apesar das particularidades socioeconômicas e culturais serem distintas entre as instituições, existem algumas características semelhantes desse fenômeno entre as diferentes áreas do saber (CUNHA; NASCIMENTO; DURSO, 2014).

Diferentes estudos e pesquisas desenvolvidos nos últimos anos (SILVA FILHO et al., 2007; ARAÚJO; VIANNA, 2011; ALKIMIN; AMARAL; LEITE, 2013; LIMA; MACHADO, 2014; RABELO, 2015; CHAVES, 2016) têm discutido sobre o tema evasão, em especial nos cursos de formação docente. Esses estudos argumentam que este fenômeno está relacionado a diferentes variáveis, tais como as dificuldades nas condições de permanência - especialmente financeiras - e a ausência de uma formação básica sólida que dê suporte aos estudantes para adquirirem os conhecimentos de nível superior. Como argumentam Alkimin, Amaral e Leite (2013), muitos estudantes têm concluído a educação básica com uma defasagem de aprendizagem muito grande, o que pode dificultar seu acompanhamento nos cursos 


\section{Atos de Pesquisa em Educação - ISSN 1809-0354 \\ Blumenau, v.14, n.2, supl.1, p.815-840, out./nov. 2019 \\ DOI: http://dx.doi.org/10.7867/1809-0354.2019v14n2s1p815-840}

de nível superior. Esse obstáculo pode resultar em muitas reprovações e, em último caso, no abandono desses estudantes do curso de graduação.

Esses problemas enfrentados em relação à aprendizagem escolar dos estudantes na educação básica trazem também preocupações acerca dos cursos de licenciatura - responsáveis pela formação de professores para esse nível de ensino , seja pelas estruturas institucionais que os comportam, seja por seus currículos e conteúdos formativos. Porém, a responsabilidade por essa base educacional fragilizada não pode ser delegada apenas aos professores e à sua formação inicial e continuada (GATTI; BARRETO; ANDRÉ, 2011), uma vez que vários fatores relacionados às condições objetivas de trabalho, salário e carreira docentes, bem como às questões de organização e gestão educacional, de políticas públicas, de condições culturais e socioeconômicas, entre outros, convergem, direta ou indiretamente, para o sucesso ou fracasso da educação escolar.

Mesmo diante dessas variáveis - e considerando-as -, é de suma importância o desenvolvimento de estudos sobre a formação de professores - tendo em vista a qualidade da educação em termos reais e não apenas formais - uma vez que, por meio desses estudos, é possível conhecer de perto quem é o futuro professor da educação básica, seus anseios, facilidades e dificuldades, alguns dos aspectos fundamentais para o delineamento de novas e efetivas estratégias de formação. Concordamos com André (2009) quando o autor afirma que é preciso pensar, juntamente com os professores, formas de atuação que busquem uma educação de qualidade para todos, e essa busca deve começar, também, com a análise da formação e das práticas dos professores.

Assim, considerando esses aspectos, objetivamos neste artigo apresentar os resultados de um estudo de caso de caráter qualitativo que teve como objetivo analisar os possíveis fatores desencadeadores da evasão acadêmica nos cursos de formação de professores, especificamente em um curso de Licenciatura em Química de uma Universidade Federal brasileira, sob a ótica dos próprios estudantes que desistiram deste curso.

Trata-se de uma instituição que, herdeira de uma longa e expressiva trajetória na educação profissional, conta atualmente com 18 cursos de licenciatura distribuídos entre 12 de seus 13 campi. Dentre eles encontra-se o curso de Licenciatura em 
Química, ofertado em 4 campi. Foco de nosso estudo, o curso de Licenciatura em Química em questão tem duração de quatro anos em regime semestral e tem como objetivo oferecer uma formação sólida e abrangente do estudante em conteúdos dos diversos campos da Química, bem como sua preparação adequada para a compreensão ampla e consistente do fenômeno educativo e das práticas escolares associadas aos saberes teóricos e práticos dessa ciência em suas diferentes dimensões ${ }^{1}$.

Assim, tendo em vista analisar o índice de evasão no curso em questão, bem como as razões pelas quais os estudantes têm tomado a decisão de abandonar o curso, realizamos uma pesquisa que envolveu parte dos sujeitos diretamente envolvidos nesse processo: os próprios estudantes.

\section{MÉTODO E PROCEDIMENTOS}

Trata-se de um estudo de caso de abordagem quanti-qualitativa, na qual dados numéricos ou estatísticos são utilizados como base para a descrição, análise e interpretação dos resultados, bem como para a garantia de legitimidade da pesquisa (LÜDKE, ANDRÉ, 2014). Inicialmente foram coletados dados referentes ao índice de evasão do curso de Licenciatura em Química, possível mediante análise documental do Relatório Analítico de Gestão disponibilizado pela própria instituição. De posse desses dados, partimos para a elaboração e aplicação de um questionário semiaberto com os estudantes que desistiram do curso, tendo em vista analisar os possíveis fatores desencadeadores de sua evasão acadêmica.

O questionário, composto por perguntas discursivas e objetivas, continha questões referentes à escolaridade, carreira profissional, condições socioeconômicas - pessoal e familiar - e bagagem cultural dos estudantes. O link do questionário, disponibilizado virtualmente por meio de uma ferramenta gratuita e de livre acesso, foi enviado ao endereço eletrônico que os estudantes disponibilizaram no momento de seu ingresso na instituição. Foram considerados participantes deste estudo os estudantes que desistiram do curso de Licenciatura em Química entre o primeiro semestre de 2011 (período em que o curso foi iniciado) e o primeiro semestre de 2016,

\footnotetext{
${ }_{1}^{1}$ Informações extraídas do Projeto Pedagógico do Curso disponível em sua página oficial na internet.
} 
período correspondente aos cinco primeiros anos do curso, tempo necessário para que quatro turmas o concluíssem. Por meio do contato com o Departamento de Educação da instituição, foram obtidos 220 endereços eletrônicos (e-mails), dos quais 6 eram duplicados - correspondentes a estudantes que se matricularam e desistiram do curso 2 vezes. Assim, ao final, foram totalizados 214 participantes, sendo esse 0 quantitativo de e-mails enviados.

Após 3 envios de mensagens aos estudantes, foram obtidas, no total, 59 participações, o que corresponde a um percentual de $27 \%$ em relação ao total de $e$ mails contatados. Segundo Marconi e Lakatos (2010), os questionários expedidos pelo pesquisador alcançam, em geral, $25 \%$ de devolução. A partir desse dado, e considerando as dificuldades que envolvem o contato com pessoas afastadas da universidade, podemos considerar que obtivemos uma quantidade significativa de respostas para o prosseguimento do estudo.

Para a análise, discussão e interpretação dos dados, realizamos a triangulação dos dados obtidos e a técnica de criação de categorias de análise (LÜDKE; ANDRÉ; 2014). Tendo como base os objetivos da pesquisa e seu referencial teórico, os dados obtidos por meio da análise documental e do questionário semiaberto foram divididos em três categorias de análise para melhor organizar a distribuição e a discussão dos resultados, sendo elas: 1) Perfil pessoal e socioeconômico; 2) Nível de escolaridade e bagagem cultural; 3) Opção pelo curso e condições objetivas e subjetivas para a permanência.

A análise e discussão dos dados apresentados neste artigo respaldam-se em um referencial teórico que discute sobre o tema (BARROS et al., 2001; ADACHI, 2009; GATTI; BARRETO, 2009; TARTUCE; NUNES; ALMEIDA, 2010; ARAÚJO; VIANNA, 2011; OLINTO, 2011; REIS; RAMOS, 2011; DEIMLING, 2014; COSTA; DIAS, 2015), bem como nos motivos, nas justificativas e nos argumentos indicados pelos participantes do estudo sobre sua evasão do curso de Licenciatura em Química em questão.

Cabe ressaltar que neste estudo as abordagens e os instrumentos metodológicos utilizados obedeceram aos procedimentos éticos estabelecidos para a pesquisa científica em Ciências Humanas, tendo em vista firmar nosso compromisso com o conhecimento científico. 


\section{A EVASÃO ACADÊMICA NO CURSO DE LICENCIATURA EM QUÍMICA: DILEMAS E DESAFIOS}

Dados disponibilizados pelo Departamento de Educação da Universidade indicam que, até abril de 2017, o curso de Licenciatura em Química contava com 163 estudantes regularmente matriculados, 33 estudantes formados e 230 estudantes desistentes (considerando os que efetivaram a matrícula). O número de estudantes desistentes é consideravelmente expressivo, principalmente quando confrontado ao número de estudantes formados: quase sete vezes maior que o número de estudantes que concluíram o curso.

A primeira turma do curso iniciou suas atividades no primeiro semestre do ano de 2011, com um total de 30 estudantes ingressantes. Desse número, desconsiderando a retenção, apenas quatro estudantes concluíram o curso quatro anos após o seu ingresso. Contudo, apesar de parecer conveniente calcular o total de evadidos apenas subtraindo o número de concluintes pelo número de ingressantes de determinado período, tal raciocínio pode nos levar ao erro, uma vez que nesse cálculo não se considera o índice de retenção dos estudantes. Segundo Araújo e Vianna (2011), as especificidades dos cursos de licenciatura - como elevadas taxas de reprovação ou desistência em determinadas disciplinas e trancamento de matrículas - geralmente levam a um atraso no término do curso para uma parcela dos estudantes. Com isso, os estudantes retidos não conseguem finalizar o curso no tempo considerado ideal - quatro anos. Assim, o cálculo da evasão, levando em consideração apenas ingressantes e concluintes, pode ser interpretado como uma falsa evasão, pois é composta pelos estudantes que evadiram, pelos estudantes que ainda irão evadir-se e por aqueles estudantes que, mesmo atrasados, concluirão o curso.

O Relatório Analítico de Gestão disponibilizado pela instituição analisa as taxas de evasão e gera dados importantes para o entendimento desse fenômeno. Ele nos dá informações sobre o semestre atual, o semestre posterior e os dois semestres subsequentes com dados sobre os concluintes, ingressantes e ativos. A partir de equações matemáticas, consegue-se identificar a taxa de evasão no curso por 


\section{Atos de Pesquisa em Educação - ISSN 1809-0354 \\ Blumenau, v.14, n.2, supl.1, p.815-840, out./nov. 2019 \\ DOI: http://dx.doi.org/10.7867/1809-0354.2019v14n2s1p815-840}

semestre/período. Segundo o documento, a taxa de evasão do primeiro semestre do curso de Licenciatura em Química (2011/1) para o segundo semestre (2011/2) foi a mais alta até o ano de 2016/1, representando 34\%. Os períodos 2013/2 e 2016/1 são os que representam menor taxa de evasão, com índice de 14\%. Os demais períodos oscilam entre $17 \%$ e $20 \%$, com uma média de 19,5\%. Trata-se de um índice muito alto que indica a necessidade de se estudar a evasão de forma profunda e conjuntural, tendo em vista a busca de possíveis soluções para amenizar a situação e diminuir o número de evadidos no curso.

\subsection{PERFIL PESSOAL E SOCIOECONÔMICO DOS ESTUDANTES}

"Para minha família, fazer uma graduação era algo muito distante de nossa realidade" (relato de um estudante desistente do curso).

Analisando os dados obtidos por meio do questionário, podemos traçar o perfil de estudante que escolhe a licenciatura e, mais especificamente, o curso de Licenciatura em Química, porém, que não o conclui, evadindo-se da instituição. A maioria dos participantes da pesquisa (31) ingressou no curso de Licenciatura em Química com idade variando entre 17 e 21 anos. Entre eles, 9 ingressaram no curso com 18 anos, 8 deles com 19 anos, e apenas 5 participantes afirmaram ter ingressado com idade variando entre 25 e 30 anos. Nenhum participante indicou ter mais de 30 anos no momento de ingresso no curso.

Essa análise também pode ser observada no estudo realizado por Gatti e Barreto (2009), as quais, tomando por base o questionário socioeconômico do Exame Nacional de Cursos (ENADE, 2005), verificaram que menos da metade dos estudantes dos cursos de licenciatura se encontram na faixa etária ideal, de 18 a 24 anos. Contudo, segundo as autoras, esses estudantes ainda são maioria, representando $46 \%$ do total. Entre 25 a 29 anos essa porcentagem é de pouco mais de $20 \%$. Proporção semelhante está na faixa entre 30 a 39 anos; a partir de então, o afunilamento é cada vez maior.

Para 52 dos participantes de nosso estudo, a idade não interferiu em sua permanência no curso; pelo contrário, aqueles que indicaram possuir, no período em que desistiram do curso, entre 18 e 19 anos de idade, afirmaram que a conclusão recente do Ensino Médio facilitou a entrada e permanência na universidade, 
apontando outros fatores para sua evasão. Houve também aqueles que alegaram que a idade não exerceu influência em sua permanência. No entanto, aos participantes que ingressaram no curso com idade variando entre 16 e 17 anos, a idade influenciou no momento da evasão, com a justificativa de não terem maturidade suficiente para a escolha do curso. Podemos observar essa ideia nos relatos de dois estudantes participantes da pesquisa: "Dezessete anos, muito jovem para entender como lidar com toda a responsabilidade que a faculdade traz"; "Dezessete anos. Acredito que dificultou porque não foi uma decisão consciente e preparada" (grifos nossos).

Sobre esse aspecto, Adachi (2009) alega que um dos motivos de insatisfação com o curso escolhido acontece pelo fato de o estudante ter que optar quase que definitivamente pela profissão que quer seguir aos 17 anos (idade em que normalmente se tem o compromisso com o vestibular e o Exame Nacional do Ensino Médio). A pouca idade e experiência de vida fazem com que o estudante escolha 0 curso de forma idealizada, baseada em critérios pouco relevantes, sem conhecer com profundidade o curso escolhido. Considerando os dados obtidos em nosso estudo, podemos inferir que o mesmo possa ter ocorrido com alguns dos estudantes evadidos do curso de Licenciatura em Química. Já entre os participantes que entraram no curso com idade mais avançada estão aqueles que alegam terem tido mais maturidade na escolha do curso, sendo outros fatores responsáveis por sua evasão, e os que indicaram ter "perdido" tempo ao entrarem tardiamente.

No que se refere ao sexo, Gatti e Barreto (2009) se deparam em seu estudo com uma feminização da docência, quando a maioria dos estudantes em cursos de licenciatura é de sexo feminino. Essa feminização só teve início durante a expansão dos ginásios, entre 1950 e 1960, e com a popularização das escolas de primeiro grau, após a Lei $n^{0} 5.692 / 71$, seguidas da perda de prestígio da profissão, da piora nas condições de trabalho e da baixa remuneração, representando um atraso com relação aos cursos de formação de professoras primárias, responsáveis pela concentração das mulheres na docência. Entretanto, no papel de professor especialista (formação em licenciaturas específicas), os homens ainda mantêm uma presença significativa. Em nosso estudo, os dados obtidos no questionário indicam um equilíbrio entre homens e mulheres que optaram pelo curso de Licenciatura em Química analisado: dos que responderam ao questionário, 30 são mulheres e 29 são homens. Para Olinto 
(2011), apesar de as mulheres representarem a maioria entre os estudantes universitários, elas são minoria em cursos de ciência e tecnologia. Assim, mesmo sendo uma licenciatura, na qual, segundo estudos, existe a predominância de mulheres, o curso analisado de Licenciatura em Química se situa na área de ciências exatas e representa uma licenciatura específica, onde, segundo esses mesmos estudos, há predominância de homens, o que pode explicar o equilíbrio entre os sexos neste curso.

No que se refere à organização familiar, 66\% dos participantes são solteiros, $26 \%$ são casados e $16 \%$ possuem de 1 a 2 filhos. Do total de participantes, $70 \%$ residem com a família (pai, mãe, companheiro/a, filhos, irmãos e parentes próximos), $15 \%$ sozinhos e $12 \%$ em habitação coletiva. No que se refere às condições de permanência na universidade, o quesito "família" também pode influenciar. Possivelmente quando se trata de esposo/a e filhos, a dedicação do estudante pode ficar dividida entre família e estudos; quando se trata dos pais e familiares, existe a dificuldade de morar longe deles, devendo o estudante arcar com despesas e dividir moradia com pessoas até então desconhecidas. Para aqueles que podem fazer essa conexão entre família e universidade, o apoio familiar pode tornar-se fator motivador para a permanência no curso.

Ao analisarmos a renda familiar dos participantes da pesquisa, podemos identificar que ela se concentra, em sua maioria, entre um e cinco salários mínimos, como podemos observar na Tabela 1:

TABELA 1: Renda mensal familiar dos participantes da pesquisa.

\begin{tabular}{lcc}
\multicolumn{1}{c}{ Renda Familiar } & № & $\%$ \\
Até 1 salário mínimo & 2 & 3,4 \\
De 1 a 2 salários mínimos & 18 & 30,5 \\
De 2 a 5 salários mínimos & 30 & 50,8 \\
De 5 a 10 salários mínimos & 9 & 15,3 \\
De 10 a 30 salários mínimos & 0 & 0 \\
Acima de 30 salários mínimos & 0 & 0 \\
Nenhuma renda & 0 & 0
\end{tabular}

Fonte: Autoria própria.

Esses dados vão ao encontro do estudo realizado por Gatti e Barreto (2009), segundo o qual 50,4\% dos estudantes que escolhem a docência estão na faixa de renda considerada média (entre 3 e 10 salários mínimos). Contudo, em nosso estudo, é muito expressivo o percentual de estudantes com renda familiar de até dois salários 
mínimos, e quase inexistente a presença de sujeitos com renda salarial de dez salários mínimos. Esses dados podem representar uma relativa ascensão das classes menos favorecidas a formações e carreiras mais qualificadas.

Outro indicativo da condição socioeconômica desprivilegiada dos estudantes que buscam a docência está no fato de se tratarem, em sua maioria, de trabalhadores. Ao serem questionados sobre terem ou não exercido atividade remunerada durante seus estudos no Ensino Médio, 62\% dos participantes da pesquisa responderam afirmativamente, sendo que, das 41 respostas obtidas a respeito das horas trabalhadas, 41,5\% indicaram terem trabalhado em tempo integral (oito horas diárias) enquanto cursavam o Ensino Médio no período noturno. Os participantes que trabalhavam até 6 horas diárias representam 22\%, enquanto os participantes que trabalhavam até 4 horas diárias correspondem a 24,4\%. Os $12,2 \%$ restantes indicaram terem exercido atividades remuneradas eventualmente, sem vínculo empregatício. As atividades exercidas indicadas pelos participantes são variadas: das 39 profissões indicadas, 30 são provenientes do setor terciário da economia (comércio, serviços gerais, atividade autônoma - babás, garçons, entre outras) e 5 abrangem outros setores. As 4 respostas restantes se enquadram nas atividades de Jovem Aprendiz. Esse mesmo padrão pode ser observado com relação à profissionalização dos pais desses estudantes, os quais, em geral, exerceram durante a maior parte de suas vidas atividades no setor terciário da economia, tais como em construção civil, em funções domésticas, no comércio, em serviços gerais e em atividades autônomas.

Os estudantes que trabalham de seis a oito horas diárias e optam por cursar o Ensino Médio no período noturno podem encontrar dificuldades em manter um bom rendimento escolar. Além da falta de tempo para o estudo, estes estudantes se deparam com o cansaço de um longo dia de trabalho, e, quando se encontram em sala de aula, dificilmente conseguem manter a concentração necessária. Aliado a isso, o tempo da hora/aula na rede pública de ensino no período noturno é menor (em média, 45 minutos), e, também por esse motivo, menos conteúdos são trabalhados em sala de aula e menos trabalhos e tarefas são solicitados aos estudantes, justamente pelo seu perfil de trabalhadores. Isso pode gerar uma séria deficiência na formação básica desses estudantes, os quais, ao ingressarem posteriormente na 


\section{Atos de Pesquisa em Educação - ISSN 1809-0354 \\ Blumenau, v.14, n.2, supl.1, p.815-840, out./nov. 2019 \\ DOI: http://dx.doi.org/10.7867/1809-0354.2019v14n2s1p815-840}

universidade, o fazem com um ritmo de estudo muito diferente daquele desenvolvido durante o Ensino Médio, o que, de certa forma, pode influenciar negativamente sua permanência no curso de graduação.

Essa análise também pode ser encontrada no estudo de Costa e Dias (2015, p. 52), segundo os quais a maior dificuldade desses estudantes está em conciliar trabalho e estudo e adaptar-se a um novo sistema de ensino, dado que o ensino superior difere em muito do Ensino Médio, exigindo maior autonomia por parte do aluno e uma base sólida de conhecimentos prévios, "aprendizados nem sempre vivenciados pelos estudantes de camadas mais populares".

Esses trabalhadores somam a maioria dos estudantes do curso de Licenciatura em Química analisado. Das 59 respostas obtidas, 32 participantes (67\%) exerceram atividade remunerada durante sua permanência no curso, e apenas 16 participantes não exerceram atividade remunerada (33\%). Desses últimos, dois participantes indicaram ter recebido algum tipo de auxílio da instituição (bolsa de Iniciação Científica, de Iniciação à Docência e/ou de monitoria), e os demais tiveram seus gastos financiados pela família.

O fato de grande parte desses estudantes (32 indicaram ter exercido algum tipo de atividade remunerada durante seus estudos) necessitar de alguma fonte de renda para arcar com suas despesas financeiras durante o curso de graduação faz ser necessário, segundo Deimling (2014), que os programas de permanência sejam mais efetivos. O Governo Federal conta com o Programa Bolsa Permanência e Auxílio Estudantil, os quais oferecem auxílio financeiro a estudantes matriculados em instituições federais de ensino superior; todavia, nem todos os estudantes são contemplados com esse auxílio, ou o auxílio que recebem (quando recebem), aliado à bolsa de iniciação científica ou à docência, ainda não é suficiente, já que muitos desses estudantes contribuem diretamente para o sustento de suas famílias (DEIMLING, 2014), como também apontado no estudo realizado por Gatti e Barreto (2009). Segundo essas autoras, $31,8 \%$ de um total de 31.023 estudantes de licenciatura trabalham e contribuem para o sustento da família, e, dentre esses, 8,1\% são os principais responsáveis pela sua manutenção. Para essas autoras, trata-se de estudantes-trabalhadores que precisam empregar seu tempo em outras ocupações, como em atividades laborais, deixando muitas vezes os estudos em segundo plano. 
Essa realidade também pode ser observada no depoimento de um dos participantes de nosso estudo: "Precisava de mais tempo para dedicar ao curso, todos os professores eram ótimos e visivelmente entendiam o que estavam ensinando, porém com tempo limitado era impossível aprender todo o conteúdo".

Para esses estudantes que trabalham e estudam existe, além da dificuldade de conciliação entre trabalho e estudo, outro fator que, para alguns, limitou sua permanência na universidade: o horário de início das aulas. Na instituição em que este curso é ofertado, as aulas têm início às $18 \mathrm{~h} 40 \mathrm{~min}$. Para aqueles que possuem uma jornada de trabalho de 8 horas diárias, seus expedientes em geral terminam às 18 horas, restando apenas 40 minutos para que se desloquem até a universidade e se alimentem antes das aulas. Para aqueles que moram em outra cidade ou que dependem de transporte público e trabalham até as 18 horas, estar dentro da sala de aula às $18 \mathrm{~h} 40 \mathrm{~min}$ torna-se inviável, como observado no depoimento de um estudante participante da pesquisa "[...] eu trabalhava na época e dependia de circular para ir pra faculdade, e dava choque de horário, e eu sempre perdia as primeiras aulas e acabava me prejudicando".

\subsection{NÍVEL DE ESCOLARIDADE E BAGAGEM CULTURAL}

"O principal objetivo da minha mãe era que todos os filhos concluíssem o ensino superior" (depoimento de estudante desistente do curso).

A partir da análise dos dados, podemos observar que a maioria dos participantes da pesquisa é proveniente de escolas públicas. Dos 59 participantes do estudo, 56 responderam ter cursado o Ensino Médio na rede pública (94,9\%) e um participante indicou ter realizado o Ensino Médio parcialmente em escola pública $(1,7 \%)$. Somente dois participantes indicaram ter cursado todo o Ensino Médio na rede privada de ensino (3,4\%). Desses estudantes, 31 (53\%) cursaram o Ensino Médio no período diurno, 9 cursaram no período noturno e 19 cursaram ao menos um ano do Ensino Médio no período noturno. Se somarmos os estudantes que fizeram todo o Ensino Médio no período noturno com aqueles que em algum momento precisaram transferir seus estudos para este período, teríamos números bastante próximos. Esses números vêm ao encontro dos dados obtidos sobre o perfil pessoal e as 
condições socioeconômicas desses estudantes, quando pelo menos 37 participantes afirmaram ter trabalhado durante o Ensino Médio. Desses, somente 10 trabalhavam até 4 horas diárias, para os quais era ainda possível manter-se no período diurno. Para os 17 estudantes que indicaram trabalhar em tempo integral e para os 9 que trabalhavam até 6 horas diárias, o Ensino Médio noturno se mostrou como a única possibilidade de continuidade dos estudos.

Quando questionados sobre as dificuldades em concluir o Ensino Médio, 37 participantes afirmam não terem tido dificuldades. Somente seis participantes admitiram ter encontrado dificuldades em concluir o Ensino Médio, seja por falta de transporte para chegar até a escola ou pelo cansaço do trabalho exercido durante o dia. Sobre essa dificuldade, destacamos algumas respostas: "Transporte da zona rural até a cidade, dificuldades financeiras em geral"; "Conciliar o cansaço de trabalhar o dia todo e prestar atenção aos conteúdos ministrados".

Ao serem questionados sobre o Ensino Médio ter ou não garantido os conhecimentos necessários para um bom desempenho no ensino superior, 12 estudantes responderam positivamente (20,3\%), 28 indicaram que o Ensino Médio não garantiu os conhecimentos necessários (47,5\%), e 19 acreditam que o Ensino Médio pouco garantiu os conhecimentos necessários para um bom desempenho no ensino superior (32,2\%). Um dos participantes que afirmou ter realizado um Ensino Médio que garantiu os conhecimentos necessários à continuação de seus estudos indicou em sua resposta acreditar que teve um ensino melhor que os demais colegas de turma, dando a entender ter sido uma exceção "Ensino com amplo conhecimento, acima da média dos estudantes que entraram na [universidade] junto comigo".

Em relação aos que consideraram que o Ensino Médio não garantiu os conhecimentos necessários ao prosseguimento dos estudos, destacamos algumas respostas:

"Infelizmente meu ensino médio foi fraquíssimo, era como se eu tivesse estudado apenas as introduções das matérias, literalmente. [...] sempre perguntei aos professores sobre alguns conteúdos, queria saber o porquê disso ou daquilo, mas eles me diziam: "ah, isso você vai ver lá na faculdade". Eu questionava: "Mas por que tem esse conteúdo no livro então?" e me respondiam: "Ah, isso é para que vocês já saibam o que vai cair lá na faculdade, no futuro". Quando o professor da [universidade] disse no primeiro dia de aula: "vou fazer uma revisão de Matemática com vocês", sinceramente, eu não entendia nada daquela revisão, mas lembrava de ter visto aquelas "coisas" no livro de ensino médio, conteúdos que meus professores diziam que eu iria aprender na faculdade" (grifos nossos). 


\title{
Atos de Pesquisa em Educação - ISSN 1809-0354 \\ Blumenau, v.14, n.2, supl.1, p.815-840, out./nov. 2019 \\ DOI: http://dx.doi.org/10.7867/1809-0354.2019v14n2s1p815-840
}

\begin{abstract}
"O ensino médio é defasado. Os conhecimentos de cálculo necessários para um curso de engenharia ou licenciatura em Química nem são explorados no ensino médio. No meu caso não houve aprofundamento. Isto não quer dizer que a atual reforma do ensino médio vai garantir esse conhecimento que faltou. Afirmo isso porque só vai se dar bem com a reforma do ensino médio quem já ingressa nele direcionado para alguma graduação, o que não é o caso da maioria dos jovens de escola pública que tem que se preocupar em ajudar em casa. Tanto no antigo quanto no novo modelo de ensino médio os conteúdos não são explorados" (grifos nossos).
\end{abstract}

São muitas coisas a serem estudadas não dá tempo de ver todas e acaba que fica conteúdo sempre pra traz, principalmente a faculdade, em 6 meses de faculdade eu estudei tudo o que apreendi durante 1 ano no ensino médio ou seja o que demorei pra aprender em 1 ano, na faculdade aprendi em 6 meses muito corrido. (grifos nossos)

"O ensino médio público é precário e sem responsabilidade com o aluno que tem certa intenção em aprender, o sistema preocupa-se apenas em manter aluno dentro da escola, porém sem efetivo resultado em aprendizagem" (grifos nossos).

Esses depoimentos revelam a ausência de uma formação sólida no Ensino Médio que dê suporte para prosseguir os estudos no ensino superior. A falta dessa base pode prejudicar consideravelmente as condições de permanência dos estudantes na universidade. Indicadores nacionais da educação, como a Prova Brasil e o Exame Nacional do Ensino Médio (ENEM), mostram que os estudantes brasileiros têm ficado abaixo da média estabelecida como básica para o Ensino Médio em disciplinas como Matemática, Química, Física e Biologia, o que indica que eles finalizam esse nível de ensino sem os requisitos mínimos necessários para dar continuidade aos estudos em nível superior (BRASIL, 2013; BRASIL, 2016a; BRASIL, 2016b). No entanto, essa problemática não fica restrita ao Ensino Médio, uma vez que a deficiência no aprendizado de conteúdos basilares pode ocorrer desde o ensino fundamental. Esse efeito "bola de neve" pode acompanhar os estudantes até seu ingresso na universidade, onde se deparam com dificuldades que evidenciam o ensino precário que receberam nas etapas anteriores do processo de escolarização. E como podemos observar, essa deficiência de formação na educação básica tem se apresentado como um dos fatores para a evasão no ensino superior.

Outro fator determinante que precisa ser levado em consideração no momento de traçar o perfil dos jovens que se matriculam nos cursos de licenciatura e não o concluem se refere à bagagem cultural desses jovens. Para Gatti e Barreto (2009, p. 166), "a escolaridade dos pais pode ser tomada como um indicador importante da bagagem cultural das famílias de que provêm os estudantes". Além disso, estudos mostram que a escolaridade dos pais pode influenciar na escolarização, carreira e rendimento acadêmico dos filhos (BARROS et al., 2001; REIS; RAMOS, 2011). Com 
relação à escolaridade dos pais, temos a seguinte realidade: $4 \%$ dos participantes são oriundos de lares analfabetos e 35\% indicaram que os pais possuem apenas o ensino fundamental. Para Gatti e Barreto (2009), o fato de esses pais terem frequentado apenas o ensino fundamental e de que seus filhos tiveram acesso ao ensino superior evidencia o processo de ascensão dessa geração a níveis mais elevados de formação. Para 31\% dos participantes, os pais cursaram o Ensino Médio, sendo que 10 deles não chegaram a concluir esta etapa. Quanto ao nível superior, 17\% dos participantes afirmaram que os pais possuem curso de graduação, contudo, 3 deles não chegaram a concluí-lo.

A partir desses dados, podemos perceber que a maior parte dos estudantes que responderam ao questionário possui pai e mãe com escolarização básica completa ou incompleta (as respostas se concentraram nos ensinos fundamental e médio). Segundo Costa e Dias (2015, p. 65), esses estudantes que representam a primeira geração a alcançar o grau acadêmico em suas famílias podem "apresentar um comportamento de pouca confiança em si mesmos, baixa expectativa sobre seu desempenho e, principalmente, um grande medo do fracasso". Esse medo em fracassar e essa pressão por parte dos próprios estudantes em concluir o curso pode levá-los a desmotivação e à falta de confiança, o que pode ocasionar em seu desânimo perante o primeiro obstáculo que lhes for imposto.

Podemos também observar as características de acesso aos bens culturais dos participantes na Tabela 2.

TABELA 2: Acesso e frequência a bens e atividades culturais dos participantes da pesquisa.

\begin{tabular}{|c|c|c|c|c|c|}
\hline & Frequentemente & $\begin{array}{c}\text { Às } \\
\text { vezes }\end{array}$ & Nunca & $\begin{array}{l}\text { Não tenho } \\
\text { interesse }\end{array}$ & $\begin{array}{c}\text { Não tenho } \\
\text { acesso }\end{array}$ \\
\hline Lê jornais & 7 & 36 & 4 & 9 & 1 \\
\hline $\begin{array}{l}\text { Lê revistas de } \\
\text { informação }\end{array}$ & 12 & 38 & 3 & 3 & 2 \\
\hline $\begin{array}{l}\text { Lê revistas } \\
\text { científicas }\end{array}$ & 8 & 30 & 10 & 3 & 6 \\
\hline $\begin{array}{l}\text { Lê livros de } \\
\text { ficção }\end{array}$ & 7 & 30 & 9 & 12 & 0 \\
\hline $\begin{array}{l}\text { Frequenta o } \\
\text { cinema }\end{array}$ & 9 & 39 & 4 & 4 & 3 \\
\hline Pratica esporte & 16 & 30 & 8 & 4 & 0 \\
\hline $\begin{array}{l}\text { Frequenta o } \\
\text { teatro }\end{array}$ & 2 & 21 & 17 & 7 & 10 \\
\hline
\end{tabular}


Atos de Pesquisa em Educação - ISSN 1809-0354

Blumenau, v.14, n.2, supl.1, p.815-840, out./nov. 2019

DOI: http://dx.doi.org/10.7867/1809-0354.2019v14n2s1p815-840

Participa de

atividades

culturais
8

30
9

Fonte: Autoria própria.

Em geral são poucos os estudantes que não possuem acesso aos itens listados acima; contudo, uma parcela considerável possui acesso restrito, indicando que nem sempre os bens culturais estão disponíveis a todos, indistintamente. Para aqueles que possuem acesso - segundo sua própria perspectiva -, o que lhes falta é, muitas vezes, 0 interesse nessas atividades.

A partir desses dados, podemos considerar que a condição socioeconômica analisada na primeira categoria desse estudo pode justificar o fato de muitos desses estudantes encontrarem dificuldades de diferentes ordens até chegarem ao ensino superior, principalmente por restrições financeiras, o que vai ao encontro do estudo realizado por Tartuce, Nunes e Almeida (2010). Segundo essas autoras, os estudantes dos cursos de licenciatura possuem, em sua maioria, poucos recursos para investir em ações que Ihes proporcionem experiências culturais mais variadas, como maior acesso a leitura, cinema, teatro, eventos culturais e viagens, por exemplo.

\subsection{OPÇÃO PELO CURSO E CONDIÇÕES OBJETIVAS E SUBJETIVAS PARA A PERMANÊNCIA}

"Infelizmente, muitos estudantes são de outras cidades e tem que bancar transporte do próprio bolso. E tem lugares, exemplo onde moro, totalmente desprovido de recursos, a prefeitura não ajuda, não temos ajuda em nada é tudo do bolso. É mais barato pagar uma faculdade a distância do que se deslocar até outra cidade" (depoimento de estudante desistente do curso, grifos nossos).

Apesar de a maioria dos participantes da pesquisa (18 deles) residir no município da instituição em questão, uma parcela significativa reside em outras cidades da mesma região. Além das cidades do mesmo Estado, alguns participantes indicaram residência em outros Estados. Na maioria dos casos, esses estudantes que vêm de outros Estados necessitam de maior apoio financeiro dos pais e familiares. Para aqueles que possuem família na cidade do curso, torna-se menos difícil (em termos financeiros) sua permanência na universidade. Contudo, para aqueles que precisam residir em repúblicas e pensionatos, a permanência torna-se mais difícil, uma vez que, além de alimentação, transporte e gastos do dia a dia, esses estudantes têm que arcar, também, com despesas de aluguel. Para aqueles que recebem algum 


\section{Atos de Pesquisa em Educação - ISSN 1809-0354 \\ Blumenau, v.14, n.2, supl.1, p.815-840, out./nov. 2019 \\ DOI: http://dx.doi.org/10.7867/1809-0354.2019v14n2s1p815-840}

auxílio, seja pela instituição, seja pela família, essa dificuldade tende a ser amenizada. Para os demais, essa condição influencia e pode ser responsável pelo abandono do curso. Dos participantes da pesquisa, somente três indicaram ter recebido o auxílio estudantil oferecido pela universidade, e sete indicaram ter recebido, durante sua permanência no curso, bolsa de iniciação científica ou de iniciação à docência. Esse tipo de bolsa pode servir não somente como auxílio, mas também como um incentivo para que o aluno permaneça no curso e o conclua.

Para aqueles que residem em cidades próximas e se deslocam para a universidade todos os dias, existe também a dificuldade com o transporte. Como os custos com transporte próprio são relativamente altos, esses estudantes recorrem ao transporte fretado que serve não somente a esta universidade como também a outras instituições de ensino superior do mesmo município. Dos estudantes oriundos de cidades próximas que utilizam esse tipo de meio de locomoção, uma parcela muito pequena estuda na universidade em questão, a qual, como já discutido, possui horário diferenciado das demais, iniciando suas aulas às 18h40min. Com isso, muitos dos estudantes desta universidade que dependem desse tipo de transporte acabam por chegar atrasados, perdendo parte da primeira aula. Segundo relato de um dos participantes da pesquisa,

"O ônibus chega todos os dias no mínimo 20 minutos atrasado pra primeira aula, depois chega por volta de uma hora da madrugada. Ao levantar as seis da manha dormindo muito pouco perdi totalmente o rendimento nos estudos e no trabalho, que mesmo sendo autônomo, tenho que dar duro pra tirar uns trocados e ter sustento em casa. [...] Passar mais de duas horas dentro de um ônibus, isso desgasta muito a vontade do aluno".

Além do fator horário, em meados de 2012, a Universidade aderiu a uma greve que durou cerca de quatro meses. Em decorrência da greve, para organizar o calendário acadêmico foram necessárias algumas medidas de compensação, como, por exemplo, ter aulas enquanto outras universidades estavam em período de férias, o que dificultou ainda mais a permanência de quem dependia de transporte fretado, pois estes não eram disponibilizados nesses períodos:

"[...] Moro em outra cidade e dependo de ônibus. Meu ônibus chegava atrasado $1 \mathrm{~h}$ todos os dias. Eu perdia uma aula inteira todos os dias. Era a única aluna dessa faculdade e ela ainda entra em greve. O motorista do ônibus jamais iria levar uma única aluna durante as férias dos demais por causa de greve. Para mim foi o fim, já estava chegando atrasada, estava com dificuldades em exatas, entra em greve, não tem transporte, não tenho ninguém que me banque 


\section{Atos de Pesquisa em Educação - ISSN 1809-0354 \\ Blumenau, v.14, n.2, supl.1, p.815-840, out./nov. 2019 \\ DOI: http://dx.doi.org/10.7867/1809-0354.2019v14n2s1p815-840}

financeiramente para terminar minha faculdade $=$ acabou. Tive de trancar sem querer, mas por necessidade" (grifos nossos).

Outra questão feita aos participantes se refere à opção pelo curso. Quando indagados sobre a principal razão que os levou a optar pelo curso de Licenciatura em Química, nota-se que essa escolha se deu principalmente por gostarem de Química (29 participantes) e por ser um curso noturno (23 participantes). Somente 15 participantes afirmaram ter optado pelo curso por querer ser professor de Química, e 8 participantes escolheram o curso por ter pouca concorrência no ingresso. Os demais participantes indicaram não se enquadrar nessas opções. A partir desses dados, podemos inferir que muitos escolhem o curso de licenciatura em Química apenas como um período transitório e de descoberta, seja para migrar para outro curso na instituição em que não se alcançou nota suficiente, seja para se descobrir enquanto profissionais, visto que ainda não se decidiram pela carreira futura. Esse dado vai ao encontro do estudo realizado por Tartuce, Nunes e Almeida (2010, p. 450), segundo as quais a opção pelo magistério muitas vezes não acontece no intuito de se realizar um projeto previamente estabelecido. Pelo contrário, a escolha é feita como uma alternativa profissional provisória, sendo muitas vezes a única escolha viável naquele momento, podendo resultar na falta de compromisso e "contribuindo para que se configure a imagem social de profissão secundária".

São poucos os participantes que ingressaram no curso de Licenciatura com o intuito de exercer a docência como profissão: apenas 11 participantes afirmaram escolher o curso por querer ser professor. As justificativas para tanto se relacionam a variados aspectos, tais como à ausência de identificação pessoal com o magistério, às condições sociais e financeiras da profissão e a sua constante desvalorização, à experiência escolar em que os estudantes percebem as dificuldades encontradas para o exercício da profissão e à influência familiar. Outro aspecto que deve ser considerado se refere ao aumento das exigências da profissão. Ao professor tem sido atribuído cada vez mais responsabilidades, tanto no que se refere às atividades pedagógicas quanto a questões que extrapolam essa temática, como a violência, cada vez mais presente nas escolas. Essas exigências e o crescente desprestígio social, aliados a baixos salários e à falta de condições de trabalho, podem afastar os jovens da docência (TARTUCE; NUNES; ALMEIDA, 2010; DEIMLING, 2014). Para Tartuce, 
Nunes e Almeida (2010), aqueles que persistem na escolha da profissão docente 0 fazem por motivos intimamente ligados a uma perspectiva altruísta e de realização pessoal, ancoradas ao desejo de ensinar, a um dom ou a uma vocação.

Sobre as expectativas com relação ao curso, 41 participantes afirmam que 0 curso atendeu as expectativas, e que, apesar de não o terem concluído por inúmeros fatores, nenhum deles estava relacionado ao curso propriamente dito. Nas justificativas são indicados problemas com transporte, conciliação trabalho-estudo, falta de identificação com o curso e com a profissão docente, fatores vocacionais e familiares, entre outros. Para aqueles que consideraram que o curso não atendeu as expectativas, justificaram esse fato com base em sua matriz curricular, considerada por eles extensa, principalmente no que se refere às disciplinas de matemática. Quando questionados quanto ao nível de dificuldade esperado antes de ingressar no curso e o nível de dificuldade encontrado, 37 dos 48 participantes que responderam a essa questão indicaram que não esperavam um nível de dificuldade tão alto quanto o encontrado. Muitos deles ainda argumentaram que não tiveram um conhecimento basilar sólido anterior que lhes desse suporte à formação superior, como podemos observar na resposta que se segue:

"Eu não esperava encontrar dificuldades, pensava estar apta para aprender mais do que eu já sabia e por isso tive dificuldades. Eu descobri no curso que não sabia nada ainda e, para estar ali naquele curso, necessitava ter uma base sólida".

Novamente, as repostas dos participantes indicam que a evasão no curso está relacionada, também, à ausência de uma formação sólida que dê base para o acesso e permanência dos estudantes do Ensino Médio aos cursos de nível superior. Como já discutido, muitos jovens finalizam o Ensino Médio sem a formação necessária para dar continuidade aos seus estudos. Essa deficiência em conhecimentos básicos pode ser evidenciada nas respostas dos participantes da pesquisa, os quais se queixam das dificuldades em avançar os períodos/semestres do curso de Licenciatura em Química analisado.

Segundo os dados obtidos, 30 participantes indicaram ter desistido do curso ainda no primeiro período, sendo que 21 deles não chegaram a concluí-lo. A partir da análise da matriz curricular, este momento do curso concentra as disciplinas consideradas mais difíceis pelos estudantes, como Cálculo I, Geometria Analítica e 
Álgebra Linear e Química Geral. Essas três disciplinas, segundo análise dos dados, concentram o maior número de reprovações. Dos participantes da pesquisa, 15 responderam ter reprovado na disciplina de Cálculo I, 21 indicaram ter reprovado na disciplina de Geometria Analítica e Álgebra Linear, e 8 reprovaram em Química Geral. Além disso, 8 dos participantes indicaram ter reprovado mais de uma vez em Cálculo I, 11 participantes indicaram ter reprovado mais de uma vez em Geometria Analítica e Álgebra Linear, e 2 voltaram a reprovar em Química Geral. Essa série de reprovações (podendo um único participante ter reprovado nas três disciplinas mais de uma vez) pode fazer com haja um desânimo por parte dos estudantes em permanecer no curso.

No segundo período do curso, momento em que são iniciadas as disciplinas pedagógicas e específicas de Química, o número de desistências diminui. Segundo os dados obtidos, oito estudantes desistiram do curso no segundo período. No terceiro período do curso houve, entre os participantes, 10 desistências, e, no quarto período, 4 desistências. Após esse período não houve índices de evasão entre os participantes da pesquisa. Contudo, é importante ressaltar que um aluno pode ter permanecido na instituição durante quatro semestres sem necessariamente estar matriculado regularmente no quarto período do curso. Os estudantes com reprovações em disciplinas que, somadas, tenham carga horária semanal igual ou superior a 16 horas/aulas permanecem retidos no período em que essas se concentram, podendo cursar disciplinas de até dois períodos subsequentes, mas não avançando para o próximo período no sistema acadêmico. Nesse sentido, os participantes da pesquisa que alegaram ter desistido do curso no quarto período poderiam não necessariamente estar regulares nesse período ou frequentando suas disciplinas. $O$ mesmo vale para o segundo e terceiro períodos.

Quando questionados se pretendem retornar ao curso de Licenciatura em Química, cinco participantes indicaram já estarem cursando novamente esta graduação, seja em outra universidade, seja em outro campus da mesma instituição. Dos demais, 19 participantes afirmaram que pretendem voltar a cursar Licenciatura em Química e 30 indicaram não ter interesse. Isso indica, em certa medida, um forte apelo vocacional a outras áreas do conhecimento e a outras profissões que não a docência, uma vez que 28 participantes desistentes do curso indicaram já ter 


\title{
Atos de Pesquisa em Educação - ISSN 1809-0354 \\ Blumenau, v.14, n.2, supl.1, p.815-840, out./nov. 2019 \\ DOI: http://dx.doi.org/10.7867/1809-0354.2019v14n2s1p815-840
}

ingressado em outras graduações das mais diversas áreas do conhecimento: Engenharia Civil, Arquitetura, Psicologia, Biomedicina, Biologia, Educação Física, Contabilidade, Agronomia, Gastronomia, Química Tecnológica, Pedagogia, Matemática e História.

O que fica bem evidente nas declarações dos participantes da pesquisa é que as dificuldades em permanecer no curso não se referem exclusivamente ao curso, mas também a diversos outros fatores que acabam, direta ou indiretamente, contribuindo para a evasão, muitos deles já discutidos neste trabalho. Ainda assim, os participantes do estudo sugerem algumas mudanças que poderiam ser realizadas para tentar diminuir a evasão neste curso, como as que se seguem:

\begin{abstract}
"Acredito que o curso seja bem estruturado e desenvolvido, no entanto percebe-se que a maioria dos discentes vem de outras cidades e estados, nesse ponto a universidade oferece pouco incentivo, tanto cultural como estrutural para que essas pessoas possam adaptar-se ao novo ambiente. Sugiro que haja minicursos de cálculo introdutório para que os discentes desenvolvam uma base melhor em cálculo e G.A.. Além disso é importante que haja a ampliação das consultas com psicólogos, pois quando precisei para melhorar meu desempenho no curso e não desistir, demorou muito o atendimento, além de ter sido bastante superficiais os atendimentos" (grifos nossos).

"Apenas algumas pequenas alterações na grade do curso. Trocar algumas disciplinas de ordem, mas não retirar nenhuma. Considero de suma importância que o aluno tenha contato com tais disciplinas, pois estamos numa faculdade que tem nome e qualidade, deve-se manter isso. O que dificulta os estudantes é a questão de ter que trabalhar ou morar longe, acabam chegando cansados e desanimados, uma alternativa para reverter a situação seria oferecer mais auxílios, incentivar à iniciação científica" (grifos nossos).
\end{abstract}

Mudanças pontuais no projeto político-pedagógico e na matriz curricular do curso - com a inclusão, por exemplo, de disciplinas/cursos introdutórios de matemática básica -, mais auxílios financeiros - para os que necessitam - e auxílio transporte - para os estudantes de outras cidades - são algumas das ações que, combinadas e aliadas a outras também destacadas ao longo deste trabalho, poderiam contribuir para a diminuição do índice de evasão neste e em tantos cursos de licenciatura no Brasil. Todavia, apesar de contribuírem para atenuar os índices de evasão acadêmica, tais ações, isoladamente, não resolveriam o problema, uma vez que são muitas as variáveis envolvidas nesse processo. Pensamos que o problema da evasão neste e em todos os demais cursos de formação inicial que formam professores e outros profissionais é conjuntural e exige ações políticas mais globais, sistemáticas e de longo prazo. 


\section{CONSIDERAÇÕES FINAIS}

A partir dos resultados obtidos, podemos observar que vários são os fatores apontados pelos estudantes como causa de sua evasão no curso de Licenciatura em Química analisado. Entre eles, destacam-se a dificuldade em conciliar trabalhoestudo, as condições socioeconômicas, a precariedade da base de conhecimento para a permanência no ensino superior e os aspectos vocacionais.

A dificuldade em conciliar trabalho e estudo foi apontada como um dos principais fatores que levam à evasão no curso em questão. Certamente, esse fator está relacionado a outro que, da mesma forma, tem impactado negativamente na permanência discente no curso de Licenciatura em Química em questão: as condições socioeconômicas dos estudantes que, por diferentes motivos, necessitam trabalhar para prover ou auxiliar nas despesas domésticas e familiares. De acordo com a análise dos dados, muitos são os estudantes que precisam conciliar estudos com trabalho; todavia, essa conciliação não ocorre de forma simples, visto que esses estudantes trabalhadores não conseguem dedicar-se ao curso da forma como deveriam. Além disso, com jornadas de trabalho extensas, esses estudantes acabam não alcançando ou mantendo um bom rendimento dentro de sala de aula pelo fato de estarem cansados física e mentalmente após exaustiva jornada de trabalho. Por esse motivo, esse aluno também fica impedido de comparecer nas horas destinadas à monitoria e aos horários de atendimento dos professores aos alunos, dificultando, assim, seu desempenho nas disciplinas.

A base escolar anterior ao ingresso na universidade foi também apontada pelos participantes como um dos principais motivos para sua desistência no curso. Advindos em sua grande maioria de escola pública, os participantes concordam ao afirmar que o Ensino Médio não garantiu ou pouco garantiu a eles os conhecimentos necessários para a permanência no ensino superior, o que resultou em dificuldades na conclusão das disciplinas do curso, em reprovações, e, consequentemente, na desistência do curso.

Outro importante aspecto observado na análise dos dados e que também interferiu na permanência desses estudantes no curso refere-se à escolha vocacional. O descontentamento com a carreira docente, foco do curso de licenciatura, ficou 


\section{Atos de Pesquisa em Educação - ISSN 1809-0354 \\ Blumenau, v.14, n.2, supl.1, p.815-840, out./nov. 2019 \\ DOI: http://dx.doi.org/10.7867/1809-0354.2019v14n2s1p815-840}

evidenciado nas respostas dos participantes da pesquisa quando afirmaram que não gostariam de "ser professor" e que, por esse motivo, desistiram do curso. Esse fator evidencia o desprestígio que a profissão docente tem sofrido ao longo dos anos e sua falta de atratividade, o que leva ao afastamento de uma parcela considerável de jovens brasileiros da docência, levando-os a cursos que possibilitem um retorno financeiro e um prestígio social maior e mais imediato.

Além desses, outros importantes aspectos foram mencionados pelos participantes como necessários para a diminuição da evasão no curso analisado, tais como: mudança no horário de início das aulas, mudanças pontuais na matriz curricular, disciplinas ou cursos introdutórios para as disciplinas com alto índice de reprovação (matemática, por exemplo); entre outros aspectos.

Considerando os resultados obtidos por esta pesquisa, entendemos que o problema da evasão nos cursos de licenciatura é um problema crônico e conjuntural que envolve variados aspectos e condições e, como tal, que não pode ser solucionado por meio de medidas isoladas e paliativas. Da mesma forma, este problema não pode ser associado somente a uma ou outra dificuldade enfrentada no percurso acadêmico, mas sim à falta de políticas que garantam a permanência desses estudantes nos cursos de formação e na carreira após a conclusão do curso. Uma das medidas necessárias para a diminuição dos índices de evasão nos cursos de licenciatura se refere à melhoria das condições de carreira e de trabalho dos professores da educação básica, promovendo, além de uma formação de qualidade, condições mínimas e o suporte humano e material necessários para a atuação desse profissional nas escolas, uma vez que a qualidade da educação e a valorização do magistério não dependem, apenas, da formação docente.

Consideramos que o presente trabalho não esgota ou encerra o debate e a reflexão sobre a evasão nos cursos de formação de professores, uma vez que o estudo é limitado a um curso específico e a uma parcela de estudantes que participaram e deram suas valiosas contribuições ao estudo. Assim, fazem-se necessários novos e mais amplos estudos que possam estudar outras e variadas realidades e condições que têm ocasionado nas altas taxas de evasão no ensino superior, tendo em vista a criação de possíveis propostas de ação que possam contribuir para a solução deste problema. Todavia, apesar das limitações do presente 
estudo, consideramos que ele acrescenta algo relevante aos estudos e pesquisas já existentes sobre a formação de professores, bem como traz importantes contribuições à compreensão deste curso de Licenciatura em Química, sob a perspectiva de seus estudantes. Com ele, esperamos também trazer contribuições a outros cursos de licenciatura desta e de outras áreas do conhecimento, proporcionando algumas reflexões para o desenvolvimento de ações que possam ser desenvolvidas para a superação da alta evasão dos estudantes que ingressam nos cursos de formação de professores.

\section{NATALIA NEVES MACEDO DEIMLING}

Pedagoga, Mestre em Educação Especial pela Universidade Federal de São Carlos e Doutora em Educação pela mesma Universidade. Professora Adjunta da Universidade Tecnológica Federal do Paraná, campus Campo Mourão.

\section{DANIELE CRISTINA DA SILVA}

Licenciada em Química pela Universidade Tecnológica Federal do Paraná, campus Campo Mourão.

\section{REFERÊNCIAS}

ADACHI, A. A. C. T. Evasão e evadidos nos cursos de graduação da UFMG. 2009. 299 p. Dissertação (Mestrado em Educação) - Universidade Federal de Minas Gerais, Belo Horizonte.

ALKIMIN, M. E. F.; AMARAL, T. R.; LEITE, N. M. G. Abandono escolar no curso de licenciatura em Matemática do IFNMG - campus januária. In: VI CONGRESSO INTERNACIONAL DE ENSINO DA MATEMÁTICA. ULBRA, Canoas - RS, 2013.

ANDRÉ, M. E. D. A. A produção acadêmica sobre formação de professores: um estudo comparativo das dissertações e teses defendidas nos anos 1990 e 2000. Formação Docente, Belo Horizonte, v. 1, n. 1, p. 41-56, ago./dez. 2009. Disponível em: <http://formacaodocente.autenticaeditora.com.br/artigo/exibir/1/7/3>. Acesso em: 10 set. 2016.

ARAÚJO, R. S.; VIANNA, D. M. A carência de professores de Ciências e Matemática da Educação Básica e a ampliação das vagas no Ensino Superior. Ciência \& Educação, v. 17, n. 4, p. 807-822, 2011.

BARROS, R. P. et al. Determinantes do desempenho educacional no Brasil. Pesquisa e Planejamento Econômico. Rio de Janeiro, v. 31, n.1, p. 1-42, 2001. 


\section{Atos de Pesquisa em Educação - ISSN 1809-0354 \\ Blumenau, v.14, n.2, supl.1, p.815-840, out./nov. 2019 \\ DOI: http://dx.doi.org/10.7867/1809-0354.2019v14n2s1p815-840}

BRASIL. Ministério da Educação (MEC). Nota explicativa resultados prova Brasil 2013. Disponível em: <

http://download.inep.gov.br/mailing/2014/nota_explicativa_prova_brasil_2013.pdf>. Acesso em: 02 abr. 2017.

BRASIL. Instituto Nacional de Estudos e Pesquisas Educacionais - INEP. Sistema de avaliação da Educação Básica 2015 - SAEB. Brasília-DF, 2016a.

BRASIL. Instituto Nacional de Estudos e Pesquisas Educacionais Anísio Teixeira (INEP). ENEM 2016: resultado individual. 2016b. Disponível em:

<http://download.inep.gov.br/educacao_basica/Enem/downloads/2016/apresentacao _final_resultados_2016.pdf>. Acesso em: 02 abr. 2017.

CHAVES, V. S. Evasão nos cursos de graduação em Física, Matemática e Química da UFRN. 2016. 100 f. Dissertação (Mestrado em Gestão de Processos Institucionais) - Universidade Federal do Rio Grande do Norte, Natal.

COSTA, S. L.; DIAS, S. M. B. A permanência no ensino superior e as estratégias institucionais de enfrentamento da evasão. Jornal de Políticas Educacionais v. 9, n.17 e 18, p. 51-60, 2015.

CUNHA, J. V. A.; NASCIMENTO, E. M.; DURSO, S. O. Razões e influências para a evasão universitária: um estudo com estudantes ingressantes nos cursos de Ciências Contábeis de instituições públicas federais da Região Sudeste. In: XIV CONGRESSO NOVAS PERSPECTIVAS NA PESQUISA CONTÁBIL. USP, $\mathrm{SP} / 2014$.

DEIMLING, N. N. M. Programa Institucional de Bolsa de Iniciação à Docência: contribuições, limites e desafios para a formação docente. 2014. 307 f. Tese (Doutorado em Educação) - Universidade Federal de São Carlos, São Carlos.

GATTI, B. A.; BARRETTO, E. S. S. Professores do Brasil: impasses e desafios. Brasília: UNESCO, 2009. 293 p.

GATTI, B. A.; BARReto, E. S. S.; ANDRÉ, M. E. D. A. Políticas docentes no Brasil: um estudo da arte. Brasília: UNESCO, 2011. $300 \mathrm{p}$.

LIMA, E.; MACHADO, L. A evasão discente nos cursos de licenciatura da Universidade Federal de Minas Gerais. Educação. Unisinos. v. 18, n. 2, p. 121-129, 2014.

LÜDKE, M.; ANDRÉ, M. E. D. A. Pesquisa em Educação: Abordagens Qualitativas. 2. ed. Rio de Janeiro: E.P.U., 2014. 128 p.

MARCONI, M. de A.; LAKATOS, E. M. Técnicas de Pesquisa: planejamento e execução de pesquisas, amostragens e técnicas de pesquisa, elaboração, análise e interpretação de dados. 7. ed. São Paulo: Atlas, 2010. 277 p. 
 \\ Blumenau, v.14, n.2, supl.1, p.815-840, out./nov. 2019 \\ DOI: http://dx.doi.org/10.7867/1809-0354.2019v14n2s1p815-840}

OLINTO, G. A inclusão das mulheres nas carreiras de ciência e tecnologia no Brasil. Inc. Soc., Brasília-DF, v. 5 n. 1, p. 68-77, 2011.

RABELO, R. P. Projeção da oferta de professores de Matemática, Física, Química e Biologia para educação básica no Brasil até 2028. 2015. 118 f. Dissertação (Mestrado em Estudos Populacionais e Pesquisas Sociais) - Escola Nacional de Ciências Estatísticas, IBGE, Rio de Janeiro.

RODRIGUES, F. S.; BRACKMANN, C. P.; BARONE, D. A. C.; Estudo da Evasão no Curso de Ciência da Computação da UFRGS. Revista Brasileira de Informática na Educação, v. 23, n. 1, p. 97-109, 2015.

REIS, M. C.; RAMOS, L. Escolaridade dos pais, desempenho no mercado de trabalho e desigualdade de rendimentos. RBE, v. 65, n. 2, p. 177-205, 2011.

SILVA FILHO, R. L. L. et al. Evasão no Ensino Superior Brasileiro. Cadernos de Pesquisa, v. 37, n. 132, p. 641-659, 2007.

TARTUCE, G. L. B. P.; NUNES, M. M. R.; ALMEIDA, P. C. A. Estudantes do ensino médio e atratividade da carreira docente no Brasil. Cadernos de Pesquisa, v. 40, n. 140, p. 445-477, 2010.

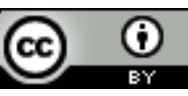

Esta obra está licenciada com uma Licença Creative Commons Atribuição 4.0 Internacional 